\title{
XIII. Guanofuracin-Leucoderma
}

Since the introduction of nitrofurans into chemotherapy by Dodd et al. in 1944, many derivatives of nitrofurans have been synthesized and tested for antibacterial activities. Among the side effects caused by these compounds, the most interesting are the atrophy of seminal tubules and depigmentation of the skin.

The former was first noticed by Prior and Fergusson and extensively studied by Paul and collaborators ${ }^{1-3)}$. It was found that Furacin inhibited the citrate formation from pyruvate in participation of acetyl CoA. The latter was observed in Japan after the topical application of Guanofuracin and has become a most interesting dermatological problem. Guanofuracin in the trade name for 5-nitro-2-furfurylidene aminoguanidine hydrochloride. This compound has high solubility in water. Takano applied this for the topical treatment of conjunctivitis and blepharitis in the forms of aqueous solution or ointment, and obtained excellent therapeutic results in most of the cases. Quite unexpectedly, one to eight months after the cessation of the therapy, there occurred depigmentation of the eyelid and eyelash in about twenty per cent of the cases (Fig. 32). Moreover, in some cases depigmentation was noticed at distant areas of the skin. In the following two years many papers on this "Guanofuracinleucoderma" appeared in both dermatological and ophthalmological literatures. The entire problem was reviewed by Iijima ${ }^{4}$.

The authors have investigated the effects of Guanofuracin on factors

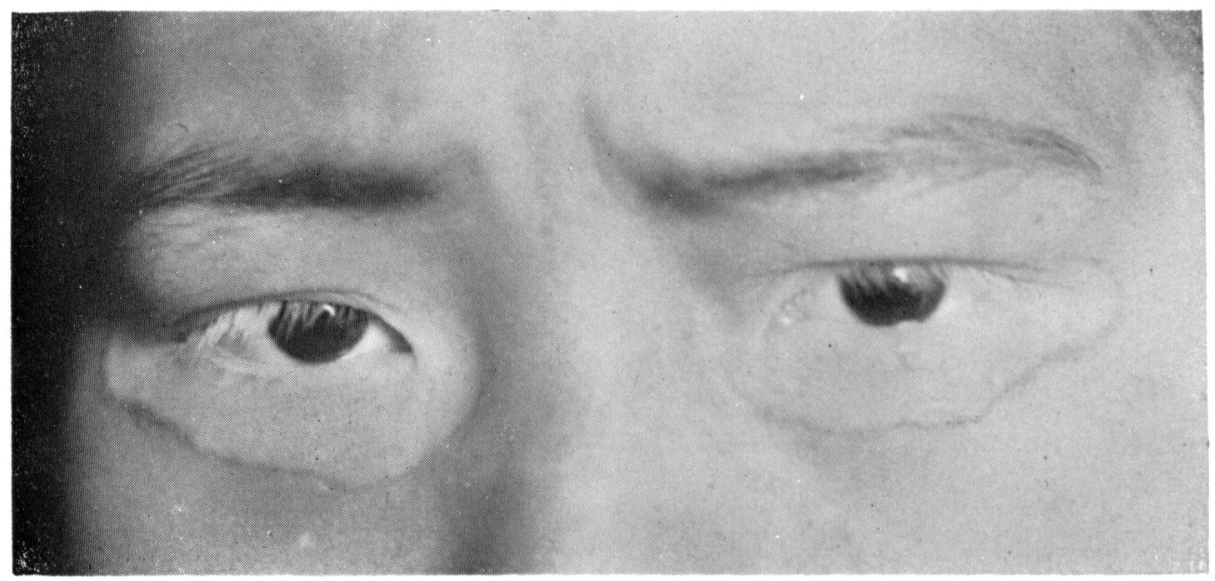

Fig. 32. Guanofuracin-Leucoderma. 
participating in the melanin production. Some of the results are given in the following.

The Effect of Guanofuracin on the Activity of Plant Tyrosinase

Experiments and Results

The enzyme was prepared from potato according to Shaaf' $\mathrm{s}^{5)}$ method. It was diluted to 2.5 times immediately before use.

$0.5 \mathrm{ml}$ of following phenolic derivatives were used as substrate: phenol $\left(10^{-2} \mathrm{M}\right)$, $p$-cresol $\left(1 / 3 \times 10^{-2} \mathrm{M}\right)$, tyrosine (suspension), catechol $\left(1 / 2 \times 10^{-2}\right.$ $\mathrm{M})$ and dopa $\left(1 / 2 \times 10^{-2} \mathrm{M}\right)$.

The activity was determined manometrically using Warburg's apparatus. To the main chamber of the vessel were added $1 \mathrm{ml}$ of $1 / 15 \mathrm{M}$ phosphate buffer ( $\mathrm{pH} 7.4$ ), $0.5 \mathrm{ml}$ of diluted enzyme solution, water and Guanofuracin to make the total of $3.5 \mathrm{ml}$. The center well contained $0.25 \mathrm{ml}$ of $40 \% \mathrm{KOH}$. After 15 to 20 minutes equilibrium at $37^{\circ} \mathrm{C}$, the substrate was added from the side arm. The oxygen consumption was followed every minute up to ten minutes in cases of $p$-cresol and catechol, at five minutes interval up to 120 minutes in cases of other substrates.

The oxygen uptake in initial five minutes period in cases of $p$-cresol and catechol, and that in initial 30 minutes for other substrates were taken for the measure of activity. As shown in Figs. 33-37, Guanofuracin inhibited the activity of potato tyrosinase in the present experimental conditions. This inhibition was reversed by the addition of copper sulfate.

Fig. 33

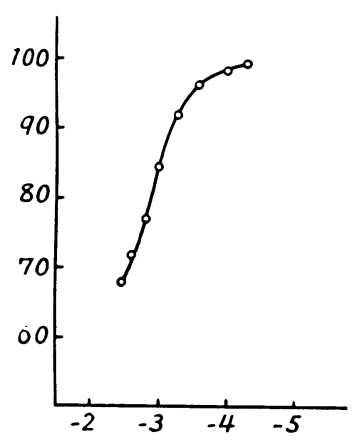

Fig. 34

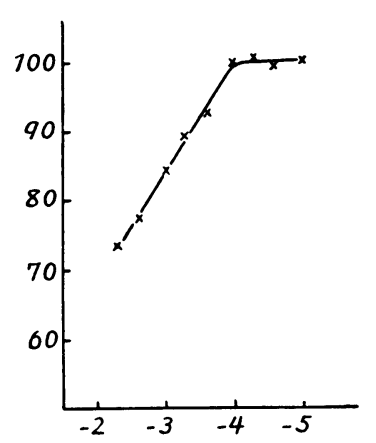

Fig. 35

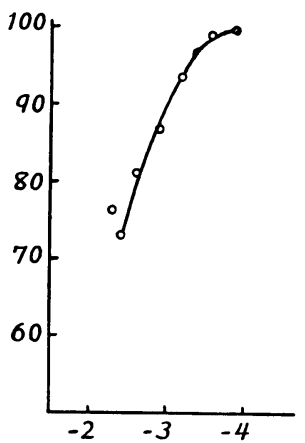

Fig. 33. Phenol-Tyrosinase. Ordinate, per cent activity; abscissa, logarithm of the final molar concentration of Guanofuracin. The results are expressed in the same way thoughout Figs. 33 to 37.

Fig. 34. Tyrosine-Tyrosinase.

Fig. 35. $b$-Cresol-Tyrosinase. 
Fig. 36

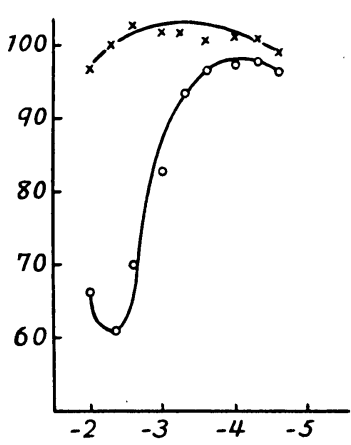

Fig. 37

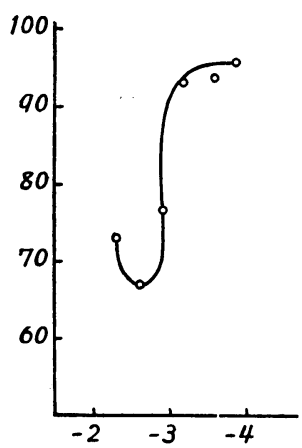

Fig. 38

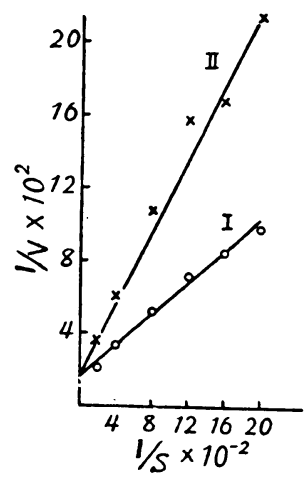

Fig. 36. Dopa-Tyrosinase. $\times-\times$ Calculated from the oxygen uptake after 30 minutes.

Fig. 37. Catechol-Tyrosinase.

Fig. 38. Ordinate, negative of the maximal reaction velocity (maximal oxygen uptake during 20 minutes period in the linear portion of reaction curves), abscissa, negative of phenol concentration.

Curve I, 1/564 M Guanofuracin ; curve II, no Guanofuracin.

In case of phenol oxidation, the negatives of the reaction velocities at various substrate concentration in the presence of $1 / 564 \mathrm{M}(50 \%$ inhibition) of Guanofuracin were plotted against the negatives of substrate concentrations. The intercept of the resulting line at the ordinate coinsided with that in the absence of Guanofuracin. Thus it was obvious that Guanofuracin is the competetive inhibitor of tyrosinase (Fig. 38).

In other experiment it was demonstrated that Guanofuracin interacted with cupric sulfate by analyzing the ultraviolet absorption spectra (Fig. $39)$.

The Effects of Chemicals Structurally Related to Guanofuracin on the Activity of Plant Tyrosinase

Experiments and Results

Eight chemicals structurally related to Guanofuracin as shown in Fig. 40 were tested for the effects on potato tyrosinase. The enzyme preparation was similar to that in the previous section except that it was somewhat more purified. $0.5 \mathrm{ml}$ of $2 \times 10^{-2} \mathrm{M} p$-cresol were used for substrate. The substances other than guanidine and aminoguanidine were dissolved in propylene glycol. The same amount of propylene glycol was added to the control flasks in place of water because reaction velocity was low in the presence of propylene glycol.

Guanidine and aminoguanidine had no effects on the activity. The 


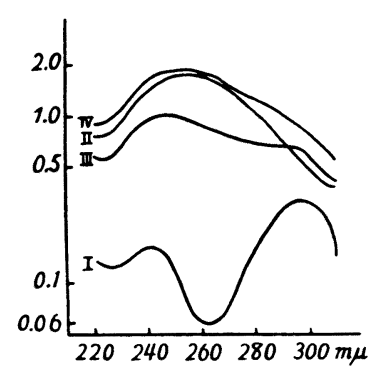

Fig. 39. The absorption was measured with Hitachi autorecording spectrophotometer. Ordinate, extinction; abscissa, wave length.

Curve I, $10^{-4} \mathrm{M} \mathrm{CuSO}_{4}$; curve II, $10^{-4} \mathrm{M}$ Guanofuracin, curve III, mixture of $10^{-4} \mathrm{M} \mathrm{CuSO}_{4}$ and same amount of equimolar Guanofuracin; curve IV, obtained by summing up curves I and II.

induction period was shortened in the presence of these two. Among other nitrofuran derivatives the most effective was the one with thiohydantoin ring in the side chain (Table XXVI \& Fig. 40).

TABLE XXVI

\begin{tabular}{c|c|c|c}
\hline Compound no.* & Solvent & Final concentration & $\begin{array}{c}\text { Inhibition } \dagger \\
(\%)\end{array}$ \\
\hline 1 & Propylene glycol & $1 / 2 \times 10 \mathrm{M}$ & 26.0 \\
2 & $"$ & $\#$ & 27.3 \\
3 & $"$ & Half saturated & 17.0 \\
4 & $"$ & $"$ & 56.0 \\
5 & $"$ & $"$ & 12.0 \\
6 & $"$ & $"$ & - \\
7 & Distilled water & $1 / 2 \times 10 \mathrm{M}$ & - \\
8 & $"$ & $"$ & $-\ddagger$ \\
9 & &
\end{tabular}

* Explained in Fig. 40. † Calculated from the oxygen consumption during initial 30 minutes period. $\ddagger$ The induction period was shortened.

The Effect of Guanofuracin on Melanoma Enzyme

\section{Experiments and Results}

The material used was the primary malignant melanoma of the leg in a 59 years old female patient. $2.4 \mathrm{~g}$ (fresh weight) of the melanoma tissue was ground with $4.8 \mathrm{ml}$ of $1 / 15 \mathrm{M}$ phosphate buffer $\mathrm{pH} 7.4$, centrifuged at 3000 r.p.m. for five minutes and the supernatant was used. The activity was measured in Warburg's apparatus using $1 \mathrm{mg}$ of dopa as substrate. Because of the paucity of the material, the determination was made only at the final concentration of $0.03 \%$ of Guanofuracin.

In flasks with Guanofuracin, the oxygen uptake in 15 minutes was $90 \%$ of the controls.

The enzyme preparation showed no activity toward tyrosine. 
Fig. 40

Compound 1. 2-(5-Nitro) furylpropenylidene-aminoguanidine hydrochloride.<smiles>NC(N)CCl</smiles>

Compound 2. Guanofuracin

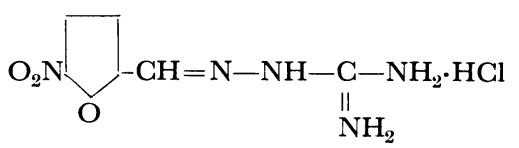

Compound 3. Bis-(5-nitrofurfurylidene)-acetoguanylhydrazon

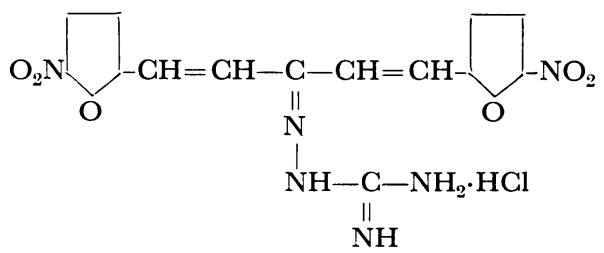

Compound 4. N-(5'-nitro-2'-furfurylidene)-1-amino-2-thiohydantoin<smiles></smiles>

Compound 5. 1-(5'-nitro-2'-furoyl)-Aminohydantoin<smiles></smiles>

Compound 6. 2-(5-nitro)-furfurylen hydrazine

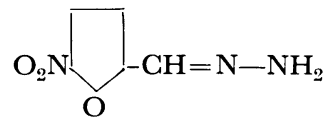

Compound 7. N-(5-nitro)-furfuryden-N'-isonicotinyl hydrazine<smiles></smiles>

Compound 8. Guanidine

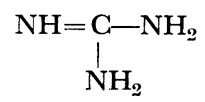

Compound 9. Aminoguanidine

$\mathrm{HN}=\mathrm{C}-\mathrm{NH}-\mathrm{NH}_{2}$
$\mathrm{NH}_{2}$ 
The Effect of Guanofuracin on the Dopa

Reaction of Human Skin

Experiments and Results

The slide glass method of Iijima and Watanabe ${ }^{6)}$ was employed.

In some of the experiments the reactions were run in the presence of $1 / 6 \times 10^{-2}$ to $1 / 6 \times 10^{-9} \mathrm{M}$ of Guanofuracin. In other experiments frozen sections were incubated in the solutions of Guanofuracin at $4^{\circ} \mathrm{C}$ or at $37^{\circ} \mathrm{C}$ before the reaction.

Contrary to expectation, the presence of Guanofuracin in the reaction mixture did not affect the result of the reaction. In some instances the reaction was somewhat accelerated, especially in the higher concentration ranges. In specimens treated with guanofuracin before the reaction, the results were not uniform.

\section{The Effect of Guanofuracin on the Red Cell GSH}

Experiments and Results

In six rabbits $1 \%$ aqueous solution of Guanofuracin was injected intravenously five times a week in the amount of $1 \mathrm{ml}$ per $\mathrm{kg}$ body weight. On the sixth day blood samples were withdrawn and red cell GSH was determined amperometrically with the method described by Bidmead and Watson ${ }^{7)}$. The red cell count, hemoglobin content and hematocrit were determined simultaneously.

As shown in Table XXVII, red cell GSH tended to be high after treatment although statistically insignificant. Moderate anemia developed in 4 of the animals.

\section{T A B L E XXVII}

Red Cell SH after Guanofuracin Injections

\begin{tabular}{|c|c|c|c|c|}
\hline \multirow{3}{*}{ Rabbits no. } & \multicolumn{4}{|c|}{$\begin{array}{l}\text { Red cell } \mathrm{SH} \\
\text { (Mg glutathione } / 100 \mathrm{ml} \text { packed red cells) }\end{array}$} \\
\hline & \multirow{2}{*}{ Before injection } & \multicolumn{3}{|c|}{ After injections for } \\
\hline & & 1 week & 2 weeks & 3 weeks \\
\hline 1 & 114.8 & 123.5 & 136.7 & 129.4 \\
\hline 3 & 136.2 & 142.3 & 119.1 & 104.9 \\
\hline 4 & 91.1 & 87.9 & 113.9 & 105.1 \\
\hline 5 & 100.3 & 112.3 & 117.9 & 94.4 \\
\hline 6 & 77.2 & 99.6 & 104.2 & 110.7 \\
\hline 7 & 81.9 & 98.2 & 104.5 & 98.8 \\
\hline Mean \pm s.d. & $100.3 \pm 22.12$ & $109.0 \pm 22.12$ & $116.1 \pm 11.98 *$ & $107.2 \pm 12.24$ \\
\hline
\end{tabular}


The Effect of Guanofuracin on Serum Tyrosine, Serum Copper and Serum Oxidase

Experiments and Results

Five rabbits were treated in the same way as in the previous section. Serum tyrosine was determined with nitrosonaphthol method of Udenfriend and Copper ${ }^{8}$. Serum copper was determined with modified Gubler et al's ${ }^{9)}$ method. The final colored complex was extracted with isoamylalcohol. Serum oxidase was determined with the method of Hornykiewicz and Niebauer ${ }^{10}$ ) with slight modification.

No changes were noticed in serum tyrosine and serum copper after the injection of Guanofuracin. The slight increase in the activity of serum oxidase was of high statistical improbability (Table XXVIII).

\section{TABLE XXVIII}

Serum Copper, Serum Tyrosine and Serum Oxidase after Guanofuracin Injections

\begin{tabular}{|c|c|c|c|c|c|}
\hline & \multirow{2}{*}{$\begin{array}{l}\text { No. of } \\
\text { determ. }\end{array}$} & \multirow{2}{*}{$\begin{array}{l}\text { Before } \\
\text { injection }\end{array}$} & \multicolumn{3}{|c|}{ After injections for } \\
\hline & & & 1 week & 2 weeks & 3 weeks \\
\hline $\begin{array}{l}\text { Serum copper* } \\
\text { (range) }\end{array}$ & 5 & $\begin{array}{l}79 \pm 5.8 \\
(73-85)\end{array}$ & $\begin{array}{c}76 \pm 16.2 \\
(63-95)\end{array}$ & $\begin{array}{l}77 \pm 8.8 \\
(63-87)\end{array}$ & $\begin{array}{l}75 \pm 7.0 \\
(63-81)\end{array}$ \\
\hline $\begin{array}{l}\text { Serum tyrosine } \dagger \\
\text { (range) }\end{array}$ & 5 & $\begin{array}{l}2.1 \pm 0.21 \\
(1.8-2.4)\end{array}$ & $\begin{array}{l}2.1 \pm 0.25 \\
(1.7-2.3)\end{array}$ & $\begin{array}{l}2.1 \pm 0.25 \\
(1.8-2.3)\end{array}$ & $\begin{array}{r}1.9 \pm 0.29 \\
(1.5-2.3)\end{array}$ \\
\hline $\begin{array}{l}\text { Serum oxidase } \\
\text { (range) }\end{array}$ & 5 & $\begin{array}{l}20.8 \pm 3.18 \\
(17.0-23.5)\end{array}$ & $\begin{array}{l}27.3 \pm 14.55 \\
(13.2-47.2)\end{array}$ & $\begin{array}{l}27.0 \pm 7.02 \S \\
(21.0-36.8)\end{array}$ & $\begin{array}{l}24.0 \pm 4.14 \\
(19.2-30.0)\end{array}$ \\
\hline
\end{tabular}

$* \mu \mathrm{g} / \mathrm{dl} . \quad \dagger \mathrm{mg} / \mathrm{dl} . \quad \ddagger \mu \mathrm{l} 0 / \mathrm{hr} . \quad \S$ four determinations.

\section{Comment}

From the results of clinical observations there hardly remains doubt that Guanofuracin actually gives rise to depigmentation of the skin without foregoing inflammatory changes. Moreover, it is possible to produce leucoderma experimentally by intracutaneous injections or iontophoresis of Guanofuracin. In leucodermatous skin the dopa reaction is negative. There is no morphological change in the ordinary structures of the epidermis and the corium other than absence of melanin. It may be interesting to examine whether the achromic melanocytes show morphological change or not.

Concerning the pathogenesis of Guanofuracin-leucoderma, the opinions of investigators are not uniform. None of the known properties of nitrofurans as well as aminoguanidine can be made responsible for the pathogenesis of the depigmentation.

Some authors maintained that Guanofuracin-leucoderma was caused 
by some change of the nervous system. This hypothesis is chiefly based on the observation that induced sweating was diminished or abolished in the leucodermatous areas. According to Yamada ${ }^{12}$, the absence in sweating was noticed in experimental Guanofuracin-leucoderma as well, and preceded the occurrence of actual depigmentation. He also stated that although the decrease in sweating was also observed in vitiligo patches, the absence of induced sweating was specific to Guanofuracin-leucoderma. It is interesting to note that the same author found no histological changes in ecrine sweat glands. The cholinesterase activity was not examined much to the regret. There was no consistent change in the morphology of nerve fibrils stained with silver impregnation methods. Impairment in the sensibility in the depigmented skin was reported in exceptional cases.

The relationship between nervous system and melanin production has been extensively investigated by many others. However, the nervous control of melanin production in human is not yet clear. It is utterly unknown what change in what part of the entire nervous system gives rise to depigmentation of the skin. So, unless substantiated by more concrete findings and theories, the present authors can not hold to the nervous theory of Guanofuracin-leucoderma.

While on the other hand, the results of manometric experiments clearly demonstrated that Guanofuracin inhibited the activity of potato tyrosinase. Similar results were obtained also by Ishida and Sano. Moreover, it was shown that the Guanofuracin was a competetive inhibitor and that it combined with cupric sulfate in vitro. This is an important finding, because most substances which inhibit plant tyrosinase by combining with copper also inhibit mammalian tyrosinase. It may be concluded that Guanofuracin-leucoderma is due to the inhibition of tyrosinase.

This conception, however, is not always confirmed by experimental results using human enzyme preparations. The effect of Guanofuracin on human melanoma enzyme could not be thoroughly investigated because of the paucity of the materials. In one experiment, the oxidation of dopa was inhibited by $10 \%$. Whether such slight inhibition is of any significance awaits further confirmation. Much more complicated was the effect of Guanofuracin on the dopa reaction. Although Yoshida ${ }^{11}$ reported that the reaction turned to negative after 5 intracutaneous injections of $0.5 \%$ solution, the results of most investigators, including present ones, did not reveal any inhibitory effects on the dopa reaction.

The negative results using human enzyme preparation may look incompatible with those obtained using plant enzymes. However, it is the opinion of the author that this contradiction is only apparent and can be explained by following considerations. 
First, it is shown that Guanofuracin competes with the substrates. Consequently, in the presence of substrates in high concentrations as in dopa reaction, the inhibition is reduced to minimum. The second, and which is the most plausible, is that mammalian enzyme is not in the state of true solution but is always attached to particulate matters of the cells. Guanofuracin interacts not only with the copper of the tyrosinase but also with other groups of cellular constituents. It is a known fact that nitrofurans in general react with $\mathrm{SH}$ group. On the other hand, the guanidine moiety of Guanofuracin is a denaturating agent for proteins and can reveal masked $\mathrm{SH}$ of proteins. It is possible that such reactions precede the one with copper of the tyrosinase and it takes considerable time for Guanofuracin to react with tyrosinase and inactivate the activity ..... a condition impossible to reproduce in dopa technique. The failure to detect inhibitory action of Guanofuracin with mammalian enzymes might be explained by such circumstances.

It cannot be neglected that injections of Guanofuracin resulted in the increase of red cell $\mathrm{SH}$ in animal experiments. Tokunaga found that red cell $\mathrm{SH}$ was high in vitiligo. The increase was more prominent in cases with shorter duration of the disease. He suggested that this played an important role in the etiology of vitiligo. Similarly the increase in red cell SH after Guanofuracin injection may play an important role in the pathogenesis of Guanofuracin-leucoderma.

\section{SUMmary}

The effects of Guanofuracin upon factors concerned in melanogenesis were studied.

Guanofuracin inhibited potato tyrosinase competetively. The inhibition was reversed by copper.

It was demonstrated spectrophotometrically that Guanofuracin interacted with cupric sulfate.

The inhibition on the melanoma enzyme was only slight and amounted only to ten per cent. The effect on the dopa reaction of the skin was negative.

It was stressed that the absence of inhibition on human enzyme preparation was only apparent, and several possible explanations were proposed.

In animal experiments, red cell $\mathrm{SH}$ increased slightly after Guanofuracin injections, while serum copper, serum tyrosine and serum oxidase showed no consistent variations.

It was proposed that Guanofuracin-leucoderma is caused by inhibition of the activity of tyrosinase. The effects on SH metabolism may play some role in the development of depigmentation. 


\section{References}

1) Paul, Paul and Kopko, Proc. Soc. Exper. Biol. Med., 1952, 79, 555.

2) Paul, Paul, Kopko, Bender and Everett, Endocrinology, 1953, 53, 585.

3) Paul, Paul, Kopko, Bryson and Harrington, J. Biol. Chem., 1954, 204, 491.

4) Iijima, Japanese Handbook of Dermatology, 1/VI. Kanehara, Tokyo, 1955, p. 215.

5) Schaaf, Arch. f. Dermat., 1936, 174, 646.

6) Iijima and Watanabe, J. Invest. Dermat., 1956, 26, 235.

7) Bidmead and Watson, Brit. J. Fxper. Path., 1952, 5, 30.

8) Udenfriend and Cooper, J. Biol. Chem., 1952, 196, 209.

9) Gubler, Lahey, Aschenbrucker, Cartwright and Wintrobe, ibid., 1952 196, 209.

10) Hornykiewicz and Niebauer, Arch. exper. Path. Pharm., 1953, 218, 448.

11) Yamada, Jap. J. Dermat., 1955, 65, 187 ; 1956, 66, 435.

12) Yoshida, Hamada and Aizawa, ibid., 1953, 63, 260. 


\section{L. Q. Z. in Pigmentary Disturbances}

As melanin is formed enzymatically in the skin, the $\mathrm{pH}$ change of the skin has a profound influence on the melanin production. Dejust ${ }^{11}$, Ropshaw $^{2)}$ and Cailliau ${ }^{3)}$ pointed to the importance of dermo-epidermal $\mathrm{pH}$ on the melanogenesis. Itô and Nakajo ${ }^{4)}$ observed that black goldfish gradually turned to red after prolonged injection of hydroquinone. As hydroquinone causes persistent alteration of the alkalization potency of rabbit skin, the inhibition of melanin formation in goldfish was surmised to be due to the same mechanism, i.e. the impairment of the alkalizing potency of the skin.

In this paper the authors will report the effects of chemicals, which are known to affect melanin production in vitro and in vivo, on the alkalizing potency of the skin.

\section{Experiments AND Methods}

The alkalizing potency of the skin was measured by the lackmus wheal reaction of Leszezynski and Falik ${ }^{5}$. The principle of this method is to make two wheals with acid and alkaline lackmus solutions and to measure the time for the wheals to become same in color.

Acid lackmus solution: $0.5 \mathrm{ml}$ of $1 \%$ lackmus solution (Merck) were added to $9.5 \mathrm{ml}$ of $\mathrm{M} / 15$ phosphate buffer ( $\mathrm{pH} 6.46$ ).

Alkaline lackmus solution: $0.5 \mathrm{ml}$ of lackmus solution were added to $9.5 \mathrm{ml}$ of distilled water. Final $\mathrm{pH}$ of the solution was 7.0.

Animal experiment : $0.1 \mathrm{ml}$ of acid solution was injected to the dorsal skin of albino rabbits intracutaneously, immediately followed by the injection of alkaline solution to the adjacent skin area. The time interval in which the colors of the two wheals become indistinguishable macroscopically was measured (L.Q.Z., abbreviation of Lackmusquaddelzeit). The results in control animals agree within the error of two minutes.

The substances to be examined were appropriately dissolved and injected sub- or intracutaneously to the remote area from the site of the L.Q.Z. test. Guanofuracin was exceptionally injected into the ear vein. Thereafter changes of the L.Q.Z. were followed up.

Clinical experiment: The method was essentially the same with the animal experiment except that the test site was the flexor surface of the upper arm.

\section{Results AND Discussion}

Effects of Chemicals on the L.Q.Z. 
1) Parahydroxyphenyl and phenyl compounds. The injection of monobenzylether of hydroquinone ( $2 \mathrm{ml}$ of $3 \%$ solution) as well as hydroquinone caused increase in the L.Q.Z., suggesting that the former is converted to the latter (Denton et al. $^{\mathbf{b})}$ ).

The injection of aniline (undiluted, $0.2 \mathrm{ml}$ ) and paraphenylenediamine which form complexes with quinones, also resulted in the prolonged L.Q.Z. On the other hand L.Q.Z. shortened after the injection of parabenzoquinone $(2.5 \mathrm{ml}$ of $2 \%$ solution).

Thus the hydroxyphenyl compounds and phenol derivatives tested affected the alkalizing potency of the skin and the resulting change in the $\mathrm{pH}$ of the skin influenced the melanogenesis by lengthening or shortening the induction period of tyrosinase.

2) Organic sulfur compounds. After the injection of BAL $(0.5 \mathrm{ml}$ of $10 \%$ solution), thiourea ( $5 \mathrm{ml}$ of $2 \%$ solution) and methylthiouracil ( $5 \mathrm{ml}$ of $2 \%$ solution intravenously) the L.Q.Z. was shortened. Benzylchloride $(0.1$ to $0.3 \mathrm{ml})$, which has anticysteinic action, caused prolongation of the L.Q.Z. It is well known that these organic sulfur compounds inhibit the activity of tyrosinase by combining with the copper of the enzyme. It is improbable that the change in the alkalizing potency of the skin is involved in the inhibitory actions of these chemicals.

3) Guanofuracin. Guanofuracin gives rise to depigmentation of eyelashes after topical application. Intravenous injection of guanofuracin $(2.5 \mathrm{ml}$ of $1 \%$ solution every other day) resulted in the shortening of the L.Q.Z. after initial two injections. However, after 7 injections the L.Q.Z. rather lengthened than the initial value. Iijima and Tokunaga ${ }^{7)}$ reported that this compound inhibited potato tyrosinase by combining with copper. However, the effect of guanofuracin on the pigment forming system of human skin is still obscure. Thus no definite results were obtained in the present investigation.

\section{L.Q.Z. in Clinical Disorders}

The results are summarized in Table XXIX. In Riehl's melanosis, lichen pigmentosus, chloasma and in nevus Ota, the L.Q.Z. was shortened in about one third of cases. It is interesting to note that in Riehl's melanosis and in Ota's nevus, the pigmentary changes occur chiefly in the dermis. In these disorders, at least in some of the cases the $\mathrm{pH}$ change and its influence on the oxidation-reduction system of the skin are thought to be the abnormal accumulation of melanin in the skin.

While on the other hand, no significant changes in L.Q.Z. were observed in vitiligo, albinism and in Addison's disease. As the lackmus wheal method reflects predominantly the $\mathrm{pH}$ change of the dermis, the disturbance in these diseases characterized by exclusively epidermal pigmentation may not be detected by this method. 
TAB LE XXIX

\begin{tabular}{|c|c|c|c|c|c|c|c|}
\hline \multirow{2}{*}{ Diseases } & \multirow{2}{*}{$\begin{array}{l}\text { No. of } \\
\text { cases }\end{array}$} & \multicolumn{6}{|c|}{$\begin{array}{l}\text { L. Q. Z. } \\
\text { (Minutes) }\end{array}$} \\
\hline & & 4 & 5 & 6 & 8 & 9 & 10 \\
\hline Normal controls & 45 & 1 & 7 & 814 & 12 & 2 & 1 \\
\hline Nevus pigmentosus & 13 & $(7.7 \%)$ & 5 & $\begin{array}{cc}2 & 4 \\
(92.3 \%)\end{array}$ & 1 & & \\
\hline Lentigo & 13 & $(7.7 \%)$ & 6 & $\begin{array}{c}4 \\
(92.3 \%)\end{array}$ & 2 & & \\
\hline Ephelides & 13 & $(15.8 \%)$ & 6 & $\begin{array}{cc}4 & 1 \\
(84.2 \%)\end{array}$ & & & \\
\hline Nevus Ota & 13 & $\begin{array}{c}4 \\
(30.7 \%)\end{array}$ & 1 & $\begin{array}{cc}4 & 4 \\
(69.3 \%)\end{array}$ & & & \\
\hline Riehl's melanosis & 10 & $\begin{array}{cc}1 & 2 \\
(30.0 \%)\end{array}$ & 3 & $\begin{array}{cc}2 & 1 \\
(70.0 \%)\end{array}$ & 1 & & \\
\hline Lichen pigmentosus & 5 & $(20.0 \%)$ & 2 & $\begin{array}{cc}1 & 1 \\
(80.0 \%)\end{array}$ & & & \\
\hline $\begin{array}{l}\text { Postiflammatory pigmenta- } \\
\text { tion }\end{array}$ & 8 & $(12.5 \%)$ & 2 & $\begin{array}{cc}2 & 3 \\
(87.5 \%)\end{array}$ & & & \\
\hline Chloasma & 35 & $\begin{array}{cc}2 & 8 \\
(28.1 \%)\end{array}$ & 8 & $\begin{array}{cc}7 & 5 \\
(69.1 \%)\end{array}$ & 4 & & $.8 \%)$ \\
\hline Addison's disease & 7 & & & $\begin{array}{cc}1 & 1 \\
(100.0 \%)\end{array}$ & 2 & & \\
\hline Acanthosis nigricans & 2 & & & $\begin{array}{c}1 \\
(100.0 \%)\end{array}$ & 1 & & \\
\hline Albinism & 1 & & 1 & & & & \\
\hline White spot disease & 2 & & 1 & 1 & & & \\
\hline Vitiligo & 47 & $\begin{array}{l}2 \\
(12.8 \%)\end{array}$ & 20 & $\begin{array}{lc}12 & 5 \\
(84.8 \% 6)\end{array}$ & 3 & & $.3 \%)$ \\
\hline Harada's disease & 1 & & 1 & & & & \\
\hline $\begin{array}{l}\text { Postinflammatory de pigmen- } \\
\text { tation }\end{array}$ & 1 & & & & & & 1 \\
\hline
\end{tabular}

\section{SuMMARY}

From the results of above-mentioned observations it was concluded that some chemicals affected melanogenesis by inducing $\mathrm{pH}$ changes of the skin. While on the other hand, in clinical disorders, factors other than $\mathrm{pH}$ changes also participate in the pathogenesis.

\section{References}

1) Dejust, Ann. Dermat., 1928, 241.

2) Ropshaw, Amer. J. Physiol., 1953, 103, 535.

3) Calliau, Ann. Dermat., 1951, 78, 42.

4) Itô and Nakajo, Tohoku J. Exper. Med., 55, Suppl., 1952, 88, 92.

5) Leczczynski and Falik, Dermat. Wschr., 1936, 103, 965.

6) Denton, Lerner and Fitzpatrick, J. Invest. Dermat., 1952, 18, 119.

7) Iijima and Tokunaga, Jap. J. Dermat., 1953, 63, 490. 


\section{Peutz's Syndrome}

In 1896 Hutchinson $^{1)}$ reported on 13-year-old identical twin sisters with numerous ephelides on the lips and the oral mucosa, emphasizing the striking similarity in distribution and size between the two girls. In 1921, Peutz $^{2}$ ) received attention for reporting on a case of ephelides on the oral mucosa in combination with polyposis in the nose and the intestine, strongly indicative of heredity. In 1946, Touraine and Couder ${ }^{\mathbf{3})}$ reported on 30 cases similar to that of Peutz, collected from literature, and one case of his own finding; in 1949, Jeghers et al. ${ }^{4)}$ gave a detailed report on 10 cases under his observation and some more cases found in literature. In 1954, Troxell ${ }^{5}$ ) stated that the number of reported cases, including one by himself, had reached 38. According to Jeghers, "this syndrome consists of two features: distinctive melanin spots of the buccal mucosa and lips - the face and digits may be involved to a variable extent, but the mouth pigmentation is the sine qua non of this portion of the syndrome; and polyposis (synonyms are adenomatosis and papillomatosis) of the small intestine. The stomach, colon and rectum may be involved, but the presence of polyps in the small intestine is the constant feature of this portion of the syndrome. And sufficient genealogic data are reported to demonstrate the hereditary nature of the syndrome, which appears to be inherited as a simple mendelian dominant. Sporadic cases also occur." Apart from these, in his treatise "Zur klinisch-ätiologischen Analyse und Systematik kleinfleckiger Pigmentierung, nebst Beschreibung einer besonderen Form von Epheliden" (1928) Siemens ${ }^{6}$ ) pointed out a specific type of freckles which occur in different regions from those of the common freckles, that is, show pigmented spots on such regions of the face as eyelids, mouth and furrows, and on the conjunctivae, oral mucosa, and palms, contending that those famous "Naevi spili der Mundschleimhaut bei Vorhandensein von Naevi spili der Haut in ausgedehnter, ungewöhnlicher Form " were not nevi, either, but ephelides. In 1929 Siemens") in Fadassohn's Handbuch described this specific type of ephelides under the designation of "Ephelides inversae", stating that the cases reported by Peutz might belong to this type. In Japan, on the other hand, the present author $^{8)}$ (1951) experienced 2 cases of ephelides-like pigmented spots on the volar surface of the fingers and the toes, the palms and soles, lips and the oral mucosa, and pointing out the similarity to Siemens' ephelides inversae, made a comparative study of them and the cases reported by Tsuru $^{9)}$ (1936), Ohmori ${ }^{10)}$ (1942) and Mori' ${ }^{11)}$ (1948) selected from Japa- 
nese literature, and those by Siemens and Szántón ${ }^{12)}$. Thereafter Moriyasu and Yoshimatsu ${ }^{13}$ ) (1952) reported similar case, but the combination with polyposis was found in none of them. Subsequently, however, Nagasu and Abe ${ }^{14)}$ (1955) reported for the first time in Japan on the cases of pigmented spots in combination with polyposis, identical with the cases of Peutz; Kitamura et al. ${ }^{15)}$ (1955) recognized polyposis in 2 of the 5 cases of pigmented spots on lips and the palms and soles of their own finding, regarding them as so-called phacomatosis, and Kawamura ${ }^{16}$ ) approved it, stating that those cases might be regarded as nevi of neural crest origin if the polyposis originated in neurinom or other cause in the neural crest ; and Yamazaki et al. ${ }^{17)}$ (1956) added 2 cases of Peutz-Jeghers' syndrome or Kitamura's phacomatosis, thus contributing to the unexpected increase of attention to this type of ephelides. Kawamura ${ }^{18)}$ has repeatedly emphasized the pigmentation on the palms and soles, being centered in crista profunda intermedia, predominantly characteristic of this disease. This finding was first described by Mori (1948), who found an analogy in the pigmented spots on the monkey's palms and soles, which was revised by Kitamura'19) (1956) who thought that the analogy, if any, was very slight because there is some difference between man's such spots and the monkey's. The present author ${ }^{8)}$ recognized in his own cases that the pigmentation in the palms and soles is centered in crista profunda intermedia, but taking a stand against Mori who takes them to be atavism, and considering this pigmentation as a type between ephelides and nevus spilus, stressed that the designation by Siemens should be followed, if tentatively. On the other side, Kitamura's view to regard this disease as nevus was followed by that of Troxell (1954), who wrote " the "phakomatoses' at least include the following :...... (the sixth or last item) Peutz's syndrome of melanoplakia and small intestinal polyposis."

The present author encountered 3 such cases during 1956. They will be reported below.

\section{Case Report}

Case 1. Y. K., 31, man. Family history: Father (63) and mother (58) were healthy. They had 8 children, of whom the eldest daughter had died of gastric ulcer (?) at 40, the second daughter (35) was healthy, the third child and the eldest son was the patient ; the second son (28), the third son (26), the third daughter (23), the fourth daughter (21) and the fourth son (16) were all healthy. The parents' was no consanguineous marriage. The patient had a daughter (5) and a son (2). His wife had had two stillbirths. History of previous illness : He had received a months' treatment of jaundice at 29. History of present illness: Since around August 1955 he had had fits of colic 2-3 times a week, had 2-3 diarrhoeas daily. Since the middle of October he had had 2-3 fits of stomach ache daily. Since the beginning of November the condition had got 
worse; he had bloody excrements and his temperature rose to $39^{\circ} \mathrm{C}$ and something. He was received in a certain hospital, where his fever was broken under various kinds of treatment for colitis ulcerosa as his case was diagnosed, but he continued to have bloody excrements. In December he was hospitalized in the Internal Department of our Hospital. Findings at the time of hospitalization: He complained chiefly of an oppressing pain in the left lower abdomen. Hemogram: Hb, (Sahli), 40\% ; R.B.C., 3,600,000 ; W.B.C., 6,600; neutrophils $58 \%$ (I, $5 \%$; II, $25 \%$; III, $23 \%$; IV, $5 \%$ ); lymphocytes, $34 \%$; monocytes, $5 \%$; eosinophils, $3 \%$. Blood sedimentation rate, $1 \mathrm{~mm}$ per hr.; blood syphilis reaction, $(-)$; uric protein and sugar, $(-)$, urobiliongen, $(-)$. Culture of feces for bacilli, (-).

Course : He made hardly any favorable progress even by cortisone and blood transfusion. Meanwhile romanoscopic and x-ray examinations revealed polyposis in the small intestine. In the meantime his case was diagnosed as Peutzs' syndrome at our Dermatological Department on the basis that he had dark brown ephelides-like pigmented spots of half or full rice-grain size on the lips, oral mucosa, palms and soles. Laboratory findings : Total serum protein, $4.82 \mathrm{gr} / \mathrm{dl}$; Albumin, 47.7\%; Globulin, $52.3 \% ; \alpha, 16.4 \% ; \beta, 11.3 \% ; \gamma, 24.6 \% ; \mathrm{A} / \mathrm{G}$, 0.91. Serum K, $4.76 \mathrm{mE} / 1 ; \mathrm{Na}, 138.40 \mathrm{mE} / 1$; Potassium tolerance test, $+28.13 \%$ (normal). Thorn's test, $-48 \%$. This patient left hospital before showing favorable progress, but it has been known that he has since ceased to give bloody excrements, recovering his almost perfect health.

Case 2. E. S., 23, man, clerk of a store. Family history: Father (54) had stomach disorder from the age of 25 through 44 or so. Mother (51) was healthy. On the father's side, grandfather had died at 32 and grandmother died of apoplexy at 71. On the mother's side, grandfather was 72, healthy, and grandmother had died at 40 . His parents had seven children : daughter, 27 ; the patient; daughter, 20 ; son, 18; daughter, 16; daughter, 13; and daughter, 10. They were all healthy. History of previous illness: He had suffered measles and whooping cough at age of 3 , and pleuritis and joint rheumatism at 6 . He had for about 4 months been suffering from optic disturbance, which had been diagnosed as opacity of the vitreous body. History of present illness: Since childhood he had a weak digestion, had always been feeling saturated and often been constipated. About 3 months before, an oculist who had diagnosed his case as opacity of the vitreous body, advised him to receive a close internal examination. Polyps being demonstrated roentgenographically at our Internal Department, he was admitted into our hospital. His main complaints were feeling of saturity, poor appetite, an oppressive feeling at the stomach, and pyrosis. He had no nausea, vomiting nor hemoptysis, though he gave a positive reaction to occult blood test. He had recently lost approximately $5 \mathrm{~kg}$. Present status: No remarkable changes were found except the pigmented spots on the lips, palms and soles (Figs. 41-43), which were quite identical with the typical ephelides inversae (Figs. 44, 45), and an oppressive feeling in the gastral region. Laboratory tests: Adrenaline test $(-)$; atropine test (-); pilocarpine test $(+)$; Robinson-Power-Kepler's water test $(-)$; total serum protein, $6.86 \mathrm{~g} / \mathrm{dl}$; Albumin, $53.88 \% ; \alpha$-Globulin, 
$9.05 \% ; \beta$-Globulin, 9.48\%; $\gamma$-Globulin, $27.59 \% ; A / G, 1.17$. Thorn's test, $-42 \%, 17-\mathrm{ks} 11.52 \mathrm{mg} /$ day (normal). Serum $\mathrm{Na} 138 \mathrm{mE} / 1$, K $4.5 \mathrm{mE} / 1$; Potassium tolerance test, $+46.8 \%$ (within 30\%-normal). Blood Wassermann test (-). Gastric juice: free hydrochloric acid, 10 ; total acidity, 20 ; occult blood test (-). X-ray examination demonstrated one polyp in the gastral region and a finding in the small intestine, suggestive of polyposis, though it was not confirmed. Histological findings: A section removed from the palm, showed same findings as those in the cases of ephelides inversae previously reported by us. That is, melanin granules are richest in the basal layer corresponding to crista profunda intermedia (Fig. 46).

Findings in the family: Father with slight ephelides had previously had severe gastroenteric troubles. He had 7 children, of whom the eldest daughter (27) was healthy, the eldest son was the patient, the second daughter (20) had pigmented spots on the oral mucosa and the left sole; serum $\mathrm{Na} 136 \mathrm{mE} / 1$, $\mathrm{K} 4.9 \mathrm{mE} / 1$, potassium tolerance test $+28.4 \%$ (normal), the second son (18) was healthy, the third daughter (16) had pigmented spots on the palm and lips, the fourth (13) and the fifth (10) daughters were all healthy. The parents' was no consanguineous marriage.

Case 3. H. I., 20, woman, student. Family history; Mother, 50, also had pigmented spots identical with those of the patient; had suffered from gastroneteric disturbances 10 years before; had been hospitalized several times for close examinations and told that she had polyposis in the stomach and intestines. Father and elder sister, 26, were healthy. History of previous illness: At age 5-6, ephelides-like pigmented spots had appeared on her face, especially lips. Similar ones had later appreared on the palms and soles, especially on the tips of fingers and toes. Her stomach and intestines had been rather weak, but they had not been with any disorders to be specially mentioned. Histoty of present illness: She had ephelides on the face, brown pigmented spots of a half-rice size on the conjunctiva bulbi of each eye; several tiny, darkbrown, ephelides-like pigmented spots around each nostril; several pigmented spots ranging in size from a point to a half rice on the lips, especially on the lower lip; and similar spots on the oral mucosa, particularly on the buccal mucosa, on the palms and soles, especially on the tips of fingers and toes. Advice was given to continue to visit our hospital for close examination, but she paid no more visit.

\section{Comment}

It is not clear whether the 3 cases (man, 17 ; man, 22 ; and woman, 31) formerly reported as ephelides inversae by the present author ${ }^{1)}$ were associated with polyposis at all, because they had not complained of gastroenteric disturbances in particular nor received x-ray examinations. Each one of the present 3 cases, as the former 3, presented specific pigmented spots, similar to those described by Siemens as pertaining to ephelides inversae. Cases 1 and 2, moreover, were clearly accompanied with polyposis; and some of the family members of Case 2 were involved 


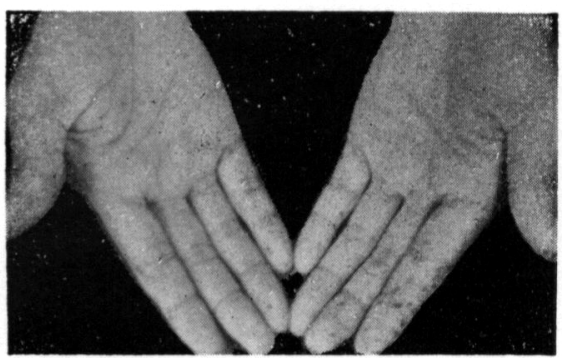

Fig. 41. Case 2.

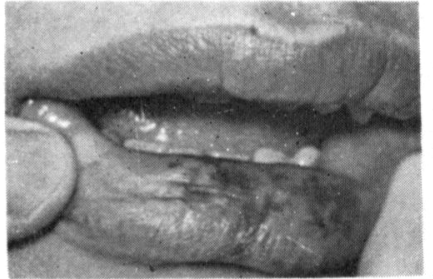

Fig. 43. Gase 2.

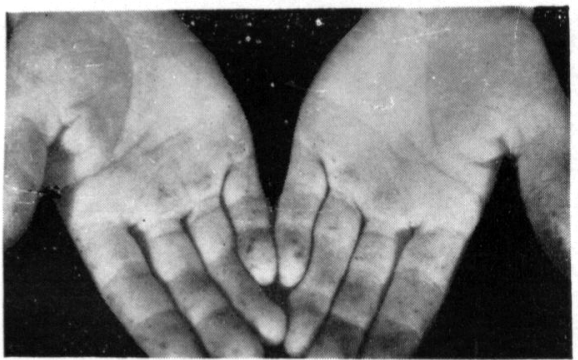

Fig. 44. Patient previously reported as ephelides inversae.

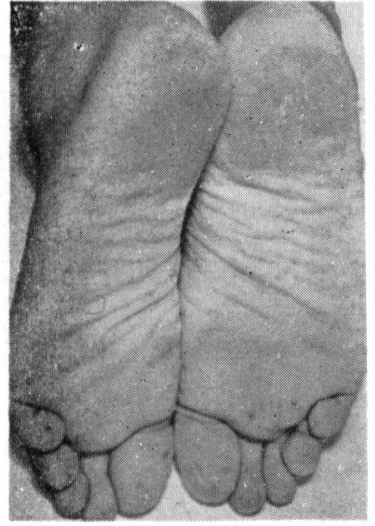

Fig. 42. Case 2.

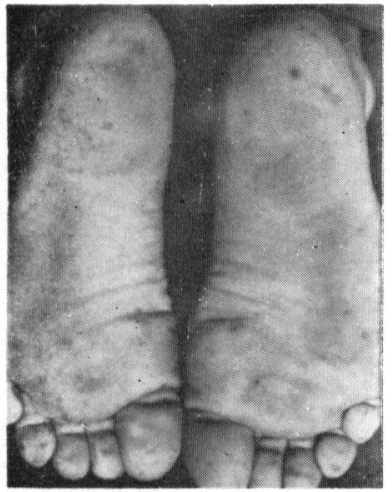

Fig. 45. Same as Fig. 44

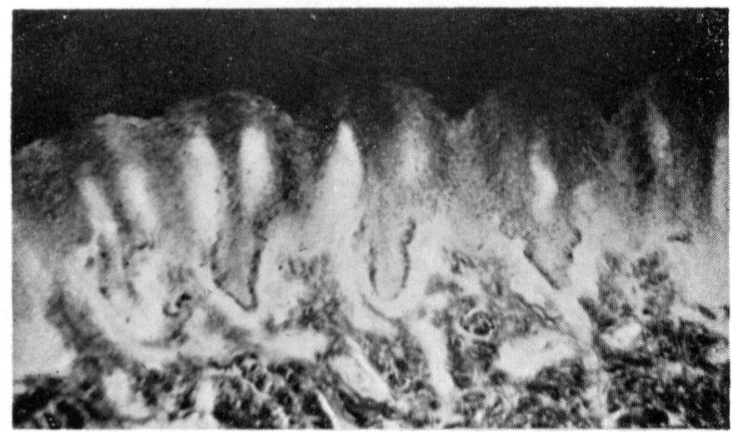

Fig. 46. Biopsy of the skin on the palm of patient previously reported as ephelides inversae, showing melanin granules in the basal layer of crista profunda intermedia. (silver impregnation method) 
in the same pigmentation. In Case 3, polyposis was not demonstrated, but it was known that her mother who had presented similar pigmented spots had had her case diagnosed as polyposis. Strictly spcaking, however, it was in the large intestine in Case 1 and in the stomach in Case 2 that polypi were evidenced; no positive evidence was given after all of the presence in the small intestine in either case. Therefore it may be doubtful whether these cases are in full accord with the definition given by Jeghers et $a l .{ }^{5}$.

Anyway these 6 cases, including the formerly reported 3, are considered, from the appearance of pigmented spots in particular regions and the very specific histological findings in those appearing especially in the palms, to fall under one and the same category, at least in the respect of pigmented spots. This will open a problem of the relationship between these pigmented spots-or ephelides inversac, as tentatively called in the sense of the word explained in the previous report-and polyposis. Supposing ephelides inversae + polyposis $=$ Peutz's Syndrome in its typical form, can there be (1) a form of Peutz's Syndrome without evident ephelides inversae but with evident polyposis, or (2) an inverse form with evidence of ephelides inversae but with doubtful presence of polyposis? Literary interpretation of the definition by Jeghers et al. clearly excludes these so-called incomplete forms from Peutz's Syndrome. In practice, however, the following must be kept in mind. In the form (1), it may be considered also that according to the view of Jeghers who makes pigmentation on the oral mucosa a necessary condition of the syndrome and merely mentions the face, and fingers as sites of possible appearance, the presence on the oral mucosa of pigmented spots, if not characteristic of ephelides inversae, is enough to satisfy the first condition. If so, the fact that we of the yellow race show a fairly high frequency $(70 \%$ according to $\mathrm{Mine}^{20)}$ ) of pigmented spots on the oral mucosa in normal persons must be taken into consideration. Then it is followed by the question whether the pigmented spots on the oral mucosa in Peutz's Syndrome possess any characteristics distinctive from those found in such normal persons. The answer is, for the present, no; there being none of such specific histological findings as in those on the palms. Accordingly, the distinction can only be made, at present, by clinical findings that the pigmented spots in Peutz's Syndrome are far marked than those in normals and that many of them are symmetrical. Thus the satisfactory solution is yet to be found for the problem of the form (1) or the so-called incomplete form of Peutz's syndrome. To turn to the form (2): There have been indeed not a few cases in which pigmentation is observed but the presence of polyposis is not evidenced. No doubt is left when polyposis is evidenced at operation or x-ray examination. But even if no polyposis 
is thereby recognized, it will not be logical to declare the absence of polyposis. The determination of the question may be made only autopsy. Thus it follows that with regard to the form (2) or the so-called incomplete form also, the question remains unsolved. Consequently, the solution of the question as to whether there can be the above-described two incomplete forms will require further close observations of a greater number of such cases ; all that may well be said at present is that the presence of the abovestated pigmentation indicates the necessity of close examination for suspected polyposis.

As for the views of Troxell ${ }^{5)}$ and Kitamura ${ }^{15)}$ who regard this disease as a phacomatosis, they are apt to entail a danger of remaining in the problem of verbal definitions unless the possible relation between these pigmented spots and polyposis is confirmed. Though it can hardly be said that histological investigations have been fully performed of papillom, Jeghers et al. consider as much as that "the synonyms of polyposis are adenomatosis and papillomatosis." However, this is not enough to make us believe, as Kawamura, ${ }^{16)}$ that polyposis is of the neural crest origin. On the other hand, the pigmented spots on the palms present, as pointed out by Mori, recognized by the present author and confirmed by Kawamura in his detailed description, very characteristic histological findings. They show that pigment is centered in crista profunda intermedia. This fact seems to have an important significance from the embroyological point of view also; it might be the key to solve the problem of Peutz's Syndrome. As against the views of Jeghers et al. who give prominence to the pigmentation on the oral mucosa, the present author wants to lay stress on the so far neglected importance of the presence of the pigmented spots on the palms - that their histological characteristics also should not be disregarded. So far as the colored races at least are concerned, the evidence and histological examination of pigmented spots on the palms is considered to have a great significance in the diagnosis of Peutz's syndrom.

\section{Summary and Conclusion}

Three cases of what appeared to be Peutz's Syndrome have been reported, a comparative discussion made with the 3 cases previously reported by the author as ephelides inversae (Siemens) and those found in literature. The definition of this syndrome by Jeghers et al. has been criticized, and the problem as to whether there can be incomplete forms of this disease, such as polyposis without associated pigmentation and the inverse, pigmentation without associated polyposis, has been discussed from the stand-point of practical clinic. It has been stressed upon that the extremely characteristic histological findings in the pigmented spots on the palms and soles have a great significance in the clarification of the 
genesis and nature as well as in the practical diagnosis of this disease.

\section{References}

1) Hutchinson, Arch. of Surg., 1896, 7, 290.

2) Peutz, Zentralblatt f. Haut- u. Gesch., 1921, 2, 275.

3) Touraine, Ann. dermat., 1945, 5, 313.

4) Jeghers, New Eng. J. Med., 1949, 241, 993, 1031.

5) Troxell, Arch. of Dermat., 1954, 70, 488.

6) Siemens, Dermat. Zeitschr., 1928, 53, 575.

7) Siemens, Jadassohn's Handb., 1929, III, 99.

8) Yoshida, Tohoku J. Exp. Med., 1952, 55, 367.

9) Tsuru, Dermat. and Urol. (Japanese), 1936, 4, 748.

10) Ohmori, Jap. J. of Dermat. (Japanese), 1942, 52, 246.

11) Mori, Clinical Dermat. Jap., 1948, 2, 215.

12) Szanto, Dermat. Wschr., 1936, 102, 24.

13) Moriyasu and Yoshimatsu, Clinic Dermat. (Japanese), 1952, 6, 397.

14) Nagasu and Abe, Clinical gastro-enterology, 1955, 3, 155.

15) Kitamura, Kojima and Sasakawa, Jap. J. of Dermat. 1956, 66, 71.

16) Kawamura, ibid., 1956, 66, 71.

17) Yamazaki, ibid., 19.56, 66, 391.

18) Kawamura, ibid., 1956, 66, 391.

19) Kitamura, ibid., 1956, 66, 391.

20) Mine, ibid., 1928, 28, 325. 


\section{Thorn's Test and Potassium Tolerance Test in Pigmentary Diseases}

The relation between melanogenesis and the endocrine glands first drew attention in connection with pathology of Addison's disease one century ago. Since then many experimental and clinical researches have been performed on the pituitary, adrenal, gonadal and thyroid glands, and the recent studies by Lerner, Fitzpatrick and Shizume on 'melanocyte-stimulating hormone' (MSH) deserve our respectful attention. But there remains many a chaotic problem yet to be cleared up. The followings are the reports of some of our studies made chiefly on the relation between melanogenesis and the pituitary-adrenocortical system using patients with various pigmentary disorders as subjects.

\section{Thorn's Test}

The results of the tests for pituitary-adrenocortical deficiency given after Reant's simplified method using subcutaneous injection of $0.3 \mathrm{cc}$ of a 1/1,000 epinephrine are shown in Table XXX. In some of the patients was combined the original Thorn's method using ACTH.

It is quite natural that the highest percentage of deficiencies was

TABLE XXX

Thorn's Test

\begin{tabular}{l|c|c}
\hline & No. of cases & Percentages of abnormal cases \\
\cline { 2 - 3 } Addison's disease & 22 & 68.2 \\
Riehl's melanosis & 42 & 50.0 \\
Lichen pigmentosus & 8 & 25.0 \\
Postinflammatory pigmentation & 18 & 33.3 \\
Chloasma & 67 & 26.9 \\
Vitiligo & 20 & 50.0 \\
Nevus pigmentosus & 11 & 18.2 \\
Nevus Ota & 11 & 36.4 \\
Albinism & 1 & 0 \\
Nevus depigmentosus & 2 & 0 \\
Ephelides & 11 & 9.1 \\
Xeroderma pigmentosum & 6 & 33.3 \\
Ephelides inversae & 2 & 100.0 \\
Acanthosis nigricans & 5 & 20.0 \\
& 97 &
\end{tabular}


attributed to Addison's disease, and it was of particular interest that a serious deficiency was revealed by Thorn's test using epinephrine and ACTH in a patient who took Addison's disease-like pigmentation following fracture of the basal bone of the skull. It was also observed that skin pigmentation was alleviated in mild cases by long-term administration of cortisone.

The explanation of the mechanism of pathogenesis of Riehl's melanosis varies with researchers: some advance an external-factor theory describing the disease to abuse of coarse cosmetics, diet, light-sensitization, etc.; others hold an internal-factor theory, and still others an eclectic theory. On the participation of the endocrine functions in the mechanism in particular there have many views published. With the results of Thorn's tests in patients with this disease, Kawagishi, Hayami, Kawajiri, Urahashi and Gondo, Yamura, and Miyagaki and Sakurane have reported that many of those patients showed a lower value of pituitary-adrenocrotical deficiency than the normal decrease range. Low blood pressure, low blood-sugar level and diminished 17-ketosteroid excretion seemed to Spira to indicate disturbed function of the adrenal glands. In our tests, we found the deficiency in about one-half of the total number of cases of this disease. Besides, a part of the tested cases showed a pigmented spot in the mucous membrane of the oral cavity and many of the cases had low blood pressure, while in some cases, the pigmentation faded by continued administration of adrenocortical hormone, adrenalin and vitamin $\mathrm{C}$ in combination. We may also mention a woman, 43, who had failed to receive treatment of the incipient Riehl's melanosis for two years until she died of Addison's disease. Such observations lead us to an inference that one of the internal causes of those diseases is the hidden presence of adrenocortical defficiency. The cases of the so-called post-inflammatory pigmentation subjected to Thorn's tests showed the deficiency in more than one-third of the cases, and it seems that the pathogenetic mechanism of this pigmentation is similar to that of Addison's disease.

Chloasma has long been drawing careful attention to its relationship to the endocrine glands, in particular to the gonads. Matthaus noticed hypertrophy of the adrenal glands during pregnancy and called it interrenalismus. Our Thorn's tests proved a deficiency in $27.4 \%$ of the patients.

More than half of our cases of vitiligo showed an deficiency by Thorn's test. It has often been reported since Addison's discription of the diesase that approximately $20 \%$ of the patients with Addison's disease have vitiligo in complication. Thus it is suspected that the function of the adrenal cortex is a cause of the change in pigmentation of the skin.

The patients with congenital pigmentary anomalies showed a rela- 
tively low percentage of deficiencies by epinephrine test, only those with nevus fusco-caeruleus Ota showed a slight deficiency. It is noteworthy however, that the 2 cases of ephelides inversae showed both a high deficiency. The limitation of the sites of the pigmented spots to the lips, the oral cavity, the palms and the soles is a characteristic of this disease which is in common with that of the Addisonian pigmentation. This fact seems to give a hint as to the pathological mechanism of melanogenesis.

\section{Serum Potassium Tolerance Test}

Of the small number of researches made so far on the relationship between melanogenesis and electrolyte metablism, only few may be cited here : the experiments carried on by Spoor and Ralli') for the fate of melanin in the skin of rats under the conditions of scheduled salt contents in the diet and adrenalectomy, the in vitro experiments by $\mathrm{Lea}^{2)}$ for testing the oxidation of premelanin substances in presence of ascorbic acid using salt diluted media, and the comparative experiments by Pann of the skin colors of eels raised in fresh water and salt water. In 1932, however, Loeb $^{3)}$ demonstrated a decrease of $\mathrm{Na}$ and $\mathrm{Cl}$ and an increase of $\mathrm{K}$ in the blood of patients with Addison's disease, and laying stress on the unbalance of $\mathrm{Na}: \mathrm{K}$, he advocated salt treatment. Subsequently, Sullivan, Marine, Baumann Collazo and Maranon Rynearson, Snell and Hansner, Thaddea, Thorn, Hashimoto, Nakazawa, Tanji, Sakamoto, Saito and Fujimaki observed a decrease in the $\mathrm{Na}$ and $\mathrm{Cl}$ contents in serum.

Experiments and Results

Method: We administered orally about $6 \mathrm{~g}$ potassic salt $(220 \mathrm{~g}$ potassium citrate, $155 \mathrm{~g}$ potassium chloride dissolved in 1,500 cc water; $50 \mathrm{cc}$ per $50 \mathrm{~kg}$ bodyweight) to patients with various pigmentary anomalies and measured the $\mathrm{K}$ and $\mathrm{Na}$ contents in the serum before and after administration, with a flame photometer. The results are shown in Table $\mathrm{XXXI}$ in which the changes in the $\mathrm{Na}$ content are not included because they were slight.

Results: The results naturally show highly advanced disturbances of mineralcorticoid function in Addison's disease, also revealing fairly advanced disturbances even in chloasma. They correspond to the results of the above-described Thorn's tests in indicating the probable participation of the adrenocortical system in these diseases. Somewhat similar tendencies are also found in Riehl's melanosis and leucomelanodermia due to monobenzylether of hydroquinone (p. 64), the difference between them corresponding to that between the dark-colored group and the fair-colored Japanese group in our experiments for the effects of sunbathing on normal skin which will be described later (p. 102). 
TABLE XXXI

Results of Potassium Tolerance Test in Various Pigmentary Diseases

\begin{tabular}{|c|c|c|c|c|}
\hline \multirow{2}{*}{ Diseases } & \multirow{2}{*}{$\begin{array}{c}\text { No. of } \\
\text { cases }\end{array}$} & \multicolumn{2}{|c|}{$\begin{array}{l}\text { Average value } \\
(\mathrm{mE} / 1)\end{array}$} & \multirow{2}{*}{ After/Before } \\
\hline & & Before & After & \\
\hline Addison's disease & 18 & 4.85 & 7.32 & 1.51 \\
\hline Chloasma & 63 & 4.54 & 6.39 & 1.43 \\
\hline Riehl's melanosis & 20 & 4.62 & 6.56 & 1.42 \\
\hline Leucomelanodermia due to $\mathrm{MBEH}$ & 14 & 4.43 & 6.55 & 1.48 \\
\hline Lichen pigmentosus & 8 & 4.76 & 6.47 & 1.36 \\
\hline Postinflammatory pigmentation & 25 & 4.57 & 6.07 & 1.33 \\
\hline Postinflammatory depigmentation & 4 & 4.40 & 6.38 & 1.45 \\
\hline Pigmentatio multiplex maculosa & 5 & 4.65 & 5.62 & 1.21 \\
\hline Complete albinism & 5 & 3.63 & 6.00 & $\because 1.82$ \\
\hline Vitiligo & 67 & 4.33 & 6.14 & 1.42 \\
\hline Ephelides & 37 & 4.51 & 5.99 & 1.33 \\
\hline Ephelides inversae & 4 & 4.42 & 5.65 & 1.28 \\
\hline Peutz's syndrome & 2 & 4.70 & 6.48 & 1.38 \\
\hline Xeroderma pigmentosum & 3 & 4.45 & 6.59 & 1.48 \\
\hline Dyschromatosis symmetrica hereditaria & 2 & 5.10 & 6.80 & $* 1.51$ \\
\hline Nevus pigmentosus & 45 & 4.44 & 5.94 & 1.34 \\
\hline Lentigines & 3 & 4.80 & 5.92 & 1.23 \\
\hline Nevus fusco-caeruleus ophthalmomaxillaris & 32 & 4.52 & 6.05 & 1.34 \\
\hline Canities & 2 & 4.15 & 5.68 & 1.37 \\
\hline Normal controls & 81 & 4.39 & 5.84 & 1.33 \\
\hline
\end{tabular}

* Single determination

That the hyperpigmentary diseases of congenital origin show almost normal values is taken for granted, because they are localized anomalies of inherited characters and have no correlation at all with adrenal functions.

The 5 patients with complete albinism showed $\mathrm{K}$ contents in the serum far lower than the lower range in normals, and one (normal in Thorn's test) of them showed an abnormal increase of $81.6 \%$ in $\mathrm{K}$ content in the serum after administration of pottasic salt. The patients with vitiligo also showed a remarkable increase, suggesting frequent incidences in them of functional insufficiency of the adrenal cortex. These results indeed should have due attention in collation with the view of Leschi that the adrenal functions in Negroes show a lower physiological range of that in Whites and the high occurrence ratio of vitiligo in the colored races (e.g. 1:36 among Negroes according to Garden), a very high ratio 
even after due consideration, as suggested by Darier and Lindberg, of a possible difference in detection rate according to a greater of smaller contrast between lesions and skin colors.

\section{SUMMARY}

In order to study on the relationship between pituitary-adrenal system and melanogenesis, Thorn's and serum potassium tolerance tests were performed in patients with various pigmentary diseases. The abnormalities were noticed in high rate in the most of acquired hyperpigmentary diseases. Thus, the participation of adrenal cortex in the regulation of skin pigmentation was presumed.

\section{References}

1) Spoor and Ralli, Endocrinology, 1944, 35, 325.

2) Lea, Nature, 1945, 155, $428 ; 1946,158,556$.

3) Loeb, Science, 1932, 76, 281. 